\title{
Testicular Spermatocytic Tumor
}

National Cancer Institute

\section{Source}

National Cancer Institute. Testicular Spermatocytic Tumor. NCI Thesaurus. Code C39921.

A testicular germ cell tumor derived from postpubertal-type germ cells. It is characterized by the presence of three cell types: round cells with eosinophilic cytoplasm, small cells with dark nucleus and a small amount of cytoplasm, and mono-or multinucleated giant cells. The neoplastic cells are not cohesive. There is an edematous stroma present; lymphocytic infiltrates are rarely seen. Most patients are older males. 